\title{
ACIDENTES POR ANIMAIS PEÇONHENTOS: ESCORPIÕES E ARANHAS
}

\author{
ENVENOMATION CAUSED BY POISONOUS ANIMALS: SCORPIONS AND SPIDERS
}

Palmira Cupo ${ }^{1}$; Marisa M. de Azevedo-Marques ${ }^{2}$ \& Sylvia Evelyn Hering ${ }^{1}$

${ }^{1}$ Docentes. Departamento de Puericultura e Pediatria. ${ }^{2}$ Docente. Departamento de Clínica Médica. Faculdade de Medicina de Ribeirão Preto - USP.

Correspondência: Unidade de Emergência do Hospital das Clínicas da FMRP-USP. 2ำandar. CEP: 14015-130. Ribeirão Preto - SP.

CUPO P; AZEVEDO-MARQUES MM \& HERING SE. Acidentes por animais peçonhentos: Escorpiões e aranhas. Medicina, Ribeirão Preto, 36: 490-497, abr./dez. 2003.

RESUMO - São abordados aspectos da fisiopatologia, clínica e terapêutica dos envenenamentos humanos, causados por escorpiões do gênero Tityus e aranhas do gêneros Phoneutria e Loxosceles, encaminhados ao Centro de Controle de Intoxicações (CCI) da U.E.-HCFMRPUSP. Quando indicada, a soroterapia antiveneno (SAV) específica deverá obedecer ao roteiro de aplicação, descrito para os acidentes ofídicos.

UNITERMOS - Escorpiões. Aranhas. Envenenamento. Antivenenos.

\section{1 - ESCORPIÕES}

\section{ACIDENTES ESCORPIÔNICOS}

No Brasil, três espécies de escorpiões do gênero Tityus têm sido responsabilizadas por acidentes humanos: T. serrulatus (escorpião amarelo), $T$. bahiensis (escorpião marrom), e T. stigmurus, sendo o T. serrulatus responsável pela maioria dos casos mais graves.

De 1982 a 2000, foram registrados no Centro de Controle de Intoxicações de Ribeirão Preto, que funciona junto à Unidade de Emergência do HC-FMRP - USP, 9228 pacientes, vítimas de picadas por escorpiões. Em 75,2\% dos casos, o escorpião envolvido no acidente foi o $T$. serrulatus, em 9,5\%, o T. bahiensis e, em 15,2\%, o agente agressor não foi identificado.

\section{Ação do Veneno}

A toxina escorpiônica é uma mistura complexa de proteínas de baixo peso molecular, associada a pequenas quantidades de aminoácidos, sem atividade hemolítica, proteolítica, colinesterásica, fosfolipásica e que não consome fibrinogênio.

Atua em sítios específicos dos canais de sódio, produzindo despolarização das terminações nervosas pós-ganglionares dos sistemas simpático, parassimpático e da medula da supra-renal, desencadeando liberação de adrenalina, noradrenalina e acetilcolina. Esses neurotransmissores, atuando em diferentes setores do organismo, são responsáveis pela maior parte dos sintomas e sinais clínicos, observados nos pacientes, sendo muito variados e mutáveis. O quadro clínico estabelecido vai depender da predominância dos efeitos ora colinérgicos ora adrenérgicos.

\section{Quadro Clínico}

Para efeitos de classificação quanto à gravidade, podemos dividir as manifestações em locais e sistêmicas, que vão definir o escorpionismo como leve, moderado ou grave.

\section{Manifestações locais}

A dor local, que ocorre praticamente em todos 
os pacientes, é de intensidade variável, até insuportável, sendo o motivo maior da busca rápida de atendimento médico. Em queimação, agulhadas ou latejante, a dor aumenta de intensidade com a palpação e pode irradiar-se para a raiz do membro acometido. Freqüentemente há parestesias. O ponto de inoculação do veneno pode não ser visível, entretanto podem ser encontrados halo eritematoso e edema discretos, sudorese e piloereção.

Nos envenenamentos mais graves, a dor é mascarada pelas manifestações sistêmicas, surgindo após melhora das condições gerais do paciente.

\section{Manifestações Sistêmicas}

A liberação de acetilcolina causa aumento das secreções das glândulas lacrimais, nasais, sudoríparas, da mucosa gástrica e do pâncreas, provocando lacrimejamento, rinorréia, sudorese e vômitos. Podem ser observados tremores, espasmos musculares, miose, bradicardia, hipotensão, priapismo e hipotermia.

Como conseqüência da liberação de catecolaminas, pode haver midríase, arritmias respiratórias e cardíacas, taquicardia, hipertensão arterial, podendo evoluir para falência cardiocirculatória e edema agudo.

Cefaléia e convulsões causadas por encefalopatia hipertensiva, e hemiplegias, relacionadas com infarto cerebral, têm sido descritas mais raramente.

\section{Classificação do Escorpionismo}

- Acidentes leves: somente presente a sintomatologia local, sendo a dor referida em praticamente $100 \%$ dos casos. Podem ocorrer vômitos ocasionais, taquicardia e agitação discretas, decorrentes da ansiedade e do próprio fenômeno doloroso.

- Acidentes moderados: além dos sintomas locais, presentes também algumas manifestações sistêmicas, isoladas, não muito intensas, como sudorese, náuseas, vômitos, hipertensão arterial, taquicardia, taquipnéia e agitação.

- Acidentes graves: as manifestações sistêmicas são bastante evidentes e intensas. Vômitos profusos e freqüentes (a intensidade e a frequiência dos vômitos são um sinal premonitório e sensível da gravidade do envenenamento), sudorese generalizada e abundante, sensação de frio, pele arrepiada, palidez, agitação psicomotora acentuada, podendo estar alternada com sonolência, hipotermia, taqui ou bradicardica, extra-sistolias, hipertensão arterial, taqui e hiperpnéia, tremores e espasmos musculares.
Pode haver evolução para choque cardiocirculatório e edema agudo do pulmão, sendo as causas mais frequientes de óbito no escorpionismo.

Em nossa região, a distribuição da gravidade dos acidentes, nas diferentes faixas de idade, tem se mantido constante no decorrer dos anos. Considerando-se o conjunto de todos os pacientes, observa-se que cerca de $97-99 \%$ dos casos podem ser considerados leves. Porém, se analisarmos apenas o grupo etário até os sete anos de idade, essa porcentagem cai para $80 \%$, ou seja, de cada 10 crianças vítimas de escorpionismo, duas apresentam quadro moderado ou grave. Também, nesse grupo etário, ocorreram cinco dos sete óbitos observados em nosso serviço.

\section{Exames Complementares}

Nos pacientes com manifestações sistêmicas, podem ser encontrados leucocitose com neutrofilia, hiperglicemia e glicosúria, hipopotassemia, hiperamilasemia, aumento da creatinoquinase e de sua fração MB. Nos casos mais graves, foi demonstrado aumento da troponina I, hoje considerado o marcador mais sensível de lesão miocárdica. Essas alterações geralmente são reversíveis dentro da primeira semana de evolução.

O eletrocardiograma é de grande auxílio na avaliação da gravidade e no acompanhamento da evolução clínica. Podem ocorrer taquicardia ou bradicardia sinusal, extra-sístoles ventriculares, distúrbios de repolarização ventricular com inversão da onda T, em várias derivações, presença de ondas U proeminentes, onda Q e infra ou supradesnivelamento do segmento ST, alterações essas semelhantes às observadas no infarto agudo do miocárdio.

Nos casos graves a ecocardiografia tem revelado hipocinesia difusa e transitória do septo interventricular e da parede posterior do ventrículo esquerdo, às vezes associada à regurgitação mitral, bem como diminuição da fração de ejeção e da porcentagem de encurtamento das fibras.

A radiografia do tórax pode evidenciar aumento da área cardíaca e sinais de edema pulmonar agudo, habitualmente assimétrico, muitas vezes unilateral.

Nos casos raros de hemiplegia, a tomografia cerebral computadorizada pode mostrar alterações compatíveis com infarto cerebral.

Técnicas de imunodiagnóstico (ELISA) têm sido utilizadas para detecção quantitativa do veneno circulante, do Tityus serrulatus nos paciente com formas moderadas e graves de escorpionismo. 


\section{Tratamento}

O tratamento visa neutralizar o mais rápido possível a toxina circulante, combater os sintomas do envenenamento e dar suporte às condições vitais do paciente. Todas as vítimas de picada de escorpião, mesmo que o quadro seja considerado leve, devem ficar em observação hospitalar nas primeiras 4 a 6 h após o acidente, principalmente as crianças. Nos casos moderados, recomenda-se, pelo menos, 24 a $48 \mathrm{~h}$ de observação e, nos casos graves, com instabilidade dos sistemas cardiorrespiratórios, está indicada a internação com monitorização contínua dos sinais vitais.

\section{Tratamento Sintomático}

Dor - O combate à dor deve ser realizado sempre, pois constitui motivo de inquietação e angústia, agravando o estado geral. Podem ser utilizados analgésicos por via oral ou parenteral, dependendo da intensidade da dor (dipirona ou mais potentes, de tipo meperidina, IM ou IV) e/ou anestésicos sem vasoconstritor, do tipo lidocaína $2 \%$ ou bupivacaína $0,5 \%$, injetados no local da picada ou sob a forma de bloqueio, na dose de 1 a $2 \mathrm{ml}$ para crianças e de 3 a $4 \mathrm{ml}$ para adultos. As infiltrações podem ser repetidas até três vezes, em intervalos de 40 a $60 \mathrm{~min}$.

Nos casos de vômitos profusos, além da hidratação parenteral (cuidadosa, devido ao risco de edema agudo), pode-se se utilizar bromopride ou metoclopramida intravenosa.

O combate à dor, como medida única adotada, é geralmente suficiente para todos os casos leves e, em adultos, para a maioria dos acidentes moderados.

\section{Tratamento Específico}

O soro antiescorpiônico (ou antiaracnídico) está formalmente indicado em todos os casos graves. Nos moderados, tem sido nossa conduta utilizá-lo apenas em crianças abaixo de sete anos, por constituírem grupo de risco. Para os demais, preconizamos, inicialmente, combater a dor e manter o paciente sob observação e, a qualquer sinal de agravamento do quadro, iniciar a soroterapia. É importante ressaltar que a gravidade do quadro já se manifesta dentro da primeira ou da segunda hora após acidente.

A dose de soroterapia, preconizada nos Manuais de Diagnóstico e Tratamento de Acidentes por Animais Peçonhentos é de 2-4 ampolas para os casos moderados e 5-10 para os graves (Secretaria de Estado da Saúde - São Paulo, 1993) e de 2-3 para os modera- dos e 4-6 para os graves (Ministério da Saúde - Fundação Nacional de Saúde, Brasília, 1999). A dose que temos utilizado é de quatro ampolas para os acidentes moderados e oito para os graves, por via intravenosa, sem diluição, durante 15 a $30 \mathrm{~min}$, lembrando que a dose é a mesma para crianças e adultos.

Os princípios da soroterapia e a rotina de aplicação dos soros antivenenos, na Unidade de Emergência do Hospital das Clínicas da FMRP-USP, constam do capítulo sobre acidentes ofídicos.

\section{Suporte às Condições Vitais}

Todos os casos graves de escorpionismo devem ser monitorizados continuamente quanto à freqüência cardíaca e respiratória, pressão arterial, oxigenação, equilíbrio ácido-base e estado de hidratação. Traçado eletrocardiográfico, contínuo ou de forma seriada, é necessário para detecção de arritmias e outras alterações cardíacas.

O manejo farmacológico dos casos graves, com bloqueadores adrenérgicos e colinérgicos, é bastante controvertido nos acidentes humanos devido à grande instabilidade do paciente, com mudanças rápidas nas manifestações clínicas, predominando ora os efeitos adrenérgicos ora os efeitos colinérgicos.

Em casos de bradicardia sinusal grave ou bloqueio AV total, que colocam a vida do paciente em risco, pode ser utilizada a atropina IV. Dados experimentais mostram que o uso de atropina pode potencializar o efeito hipertensor e agravar a intensidade do edema agudo pulmonar, induzido pelo veneno escorpiônico. Na vigência de insuficiência cardíaca congestiva e/ou edema pulmonar, o tratamento deve ser de suporte, com diuréticos e oxigenioterapia. Nos casos mais graves, e na presença de hipotensão ou choque, está indicado o uso de aminas vasoativas (dobutamina) e, se necessário, ventilação mecânica. Em casos de hipertensão arterial mantida, tem sido preconizado o uso de alfa bloqueadores, vasodilatadores e inibidores do canal de cálcio. Em nossa experiência, a hipertensão, mesmo quando acentuada, tem caráter transitório, cedendo espontaneamente, após soroterapia específica, nas primeiras $6 \mathrm{~h}$.

\section{Complicações e Prognóstico}

Prognóstico geralmente bom, principalmente nos casos leves e moderados. Nos casos graves, as primeiras $24 \mathrm{~h}$ são críticas, período no qual podem surgir as temidas complicações cardiocirculatórias e pulmonares, que podem levar o paciente à morte. 


\section{BIBLIOGRAFIA CONSULTADA}

1- ABROUGH F; BOUDJDARIA R; BELGHITI M; NOUIRA S \& BOUCHOUCHA S. Cardiac dysfunction and pulmonary edema following scorpion envenomation. Chest 100: 10571059, 1991.

2- ABROUGH F; AYARI M; NOUIRA S; GAMRA H; BOUDJDARIA R; ELATROUS S; BEN FARHAT M \& BOUCHOUCHA S. Assessment of left ventricular function in severe scorpion envenomation: combined hemodynamic and echodoppler study. Int Care Med 21: 629-635, 1995.

3- AMARAL CFS; BARBOSA AJA; LEITE VHR; TAFURI WL \& REZENDE NA. Scorpion sting induced pulmonary oedema: evidence of increased alveolocapillary membrane permeability. Toxicon 32: 999-1003, 1994.

4- AMARAL CFS;DIAS MB; CAMPOLINA D; PROIETTI EA \& REZENDE NA. Children whit adrenergic manifestations of envenomation after Tityus serrulatus scorpion sting are protected from early anaphylactic antivenom reaction. Toxicon 32, 211-215,1994.

5- AMARAL CFS; LOPES JA; MAGALHÃES RA \& REZENDE NA. Electrocardiographic enzymatic and echocardiographic evidence of myocardial damage after Tityus serrulatus scorpion poisoning. Am J Cardiol 67: 655-657, 1991.

6- AMARAL CFS \& REZENDE NA. Both cardiogenic and noncardiogenic factors are involved in the pathogenesis of pulmonary oedema after scorpion envenoming. Toxicon 35:997-998, 1997.

7- AMARAL CFS; REZENDE NA \& FREIRE-MAIA L. Acute pulmonary edema after Tityus serrulatus sting in children . Am J Cardiol 71: 242-245, 1993.

8- BRASIL.MINISTÉRIO DA SAÚDE. Escorpionismo. Análise Epidemiológica. Coordenação de Controle de Zoonoses e Animais Peçonhentos. Brasília-DF, 1991.

9- BRASIL. MINISTÉRIO DA SAÚDE. FUNDAÇÃO NACIONAL DA SAÚDE. Manual de Diagnóstico e Tratamento de Acidentes por Animais Peçonhentos. Brasília, 1998.

10 - BRASIL. SECRETARIA DE ESTADO DA SAÚDE. Manual de Vigilância Epidemiológica. Acidentes por Animais Peçonhentos. São Paulo, 1993.

11- BUCARETCHI F; BARACAT ECE; NOGUEIRA RJN; CHAVES A; ZAMBRONE FAD; FONSECA MRCC \& TOURINHO FSA. Comparative study of severe scorpion envenomation in children caused by Tityus bahiensis and Tityus serrulatus. Rev Inst Med Trop São Paulo 37: 331-336, 1995.

12- CUPO P; AZEVEDO-MARQUES MM \& HERING SE. Escorpionismo. In: CARDOSO JLC; FRANÇAFOS; FAN FW; MÁLAQUE CM \& HADDAD Jr. V, eds. Animais peçonhentos no Brasil. Biologia, clínica e terapêutica dos acidentes. Sarvier, São Paulo, p.182-197, 2003.

13- CUPO P; AZEVEDO-MARQUES MM; MENEZES JB \& HERING SE. Reações de hipersensibilidade imediatas após uso endovenoso de soros antivenenos: valor prognóstico dos testes de sensibilidade intradérmicos. Rev Inst Med Trop São Paulo 33: 115-122, 1991.
14- CUPO P; AZEVEDO-MARQUES MM; SARTI W \& HERING SE. Proposal of abolition of the skin sensitivity test before equine rabies immune globulin application. Rev Inst Med Trop São Paulo 43: 51-53, 2001.

15- CUPO P \& HERING SE. Cardiac troponin I release after severe scorpion envenoming by Tityus serrulatus. Toxicon 40: 823-830, 2002.

16- CUPO P; JURCA M; AZEVEDO-MARQUES MM; OLIVEIRA JSM \& HERING SE. Severe scorpion envenomation in Brazil Clinical laboratory and anatomopathological aspects. Rev Inst Med Trop São Paulo 36: 67-76, 1994.

17- ELATROUS S; NOUIRAS; BESBESOUANES L; BOUSSARSAR M; BOUKEF R; MARGHLI S \& ABROUG F. Dobutamine in severe scorpion envenoming - effects on standard hemodynamics right ventricular performance and tissue oxygenation. Chest 116: 748-753, 1999.

18- FREIRE-MAIA L \& CAMPOS JA. Pathophysiology and treatment of scorpion poisoning. In: OWNBY CL \& ODELL GV, eds. Natural toxins. Pergamon Press, Oxford, p. 139159, 1989.

19- GOYFFON M; VACHON M \& BROGLIO NE. Epidemiological and clinical characteristics of the scorpion envenomation in Tunisia. Toxicon 20: 337-344, 1982.

20- GUERON M; STERN J \& COHEN W. Severe myocardial damage and heart failure in scorpion sting. Report of five cases. Am J Cardiol 19: 719-726, 1967.

21- GUERON M \& YARON R. Cardiovascular manifestations of severe scorpion sting. Clinicopathological correlation. Chest 57: 156-162, 1970.

22- HERING SE; AZEVEDO-MARQUES MM \& CUPO P. Escorpionismo. In: SCHVARTSMAN S, ed. Plantas venenosas e animais peçonhentos. Sarvier, São Paulo, p. 216-227, 1992.

23- HERING SE; JURCA M; VICHI FL; AZEVEDO-MARQUES MM \& CUPO P. "Reversible cardiomyopathy" in patients with severe envenoming by Tityus serrulatus - evolution of enzymatic; electro and echocardiographic alterations. Ann Trop Pediatr 13: 191-200, 1993.

24- KARNAD DR. Haemodynamic patterns in patients with scorpion envenomation. Heart 79: 485-489, 1998.

25- OLORTÉGUI-CHAVEZ C; FONSECA SCG; CAMPOLINA D; AMARAL CFS \& DINIZ CR. ELISA for the detection of toxic antigens in experimental and clinical envenoming by Tityus serrulatus scorpion venom. Toxicon 32: 1649-1656, 1994.

26- RAHAV G \& WEISS T. Scorpion sting-induced pulmonary edema: scintigraphic evidence of cardiac dysfunction. Chest 97: 1478-1480, 1990.

27- REZENDE NA; DIAS MB; CAMPOLINAD; OLORTÉGUI-CHAVEZ C; DINIZ CR \& AMARAL CFS. Efficacy of antivenom therapy for neutralizing circulating venom antigens in patients stung by Tityus serrulatus scorpions. Am J Trop Med Hyg 52: 277-280, 1995. 


\section{2- ARANHAS}

No Brasil, existem três gêneros de aranhas de importância médica: Phoneutria, Loxosceles e Latrodectus. Os acidentes causados por Lycosa (aranha-da-grama), bastante freqüentes, e pelas Megalomorphae (caranguejeiras), muito temidas, são destituídos de maior importância.

São animais carnívoros, alimentando-se principalmente de insetos, como grilos e baratas. Muitas têm hábitos domiciliares e peridomiciliares.

Foram registrados, no CCI de Ribeirão Preto, e atendidos na Unidade de Emergência do HCFMRPUSP pelas equipes de Clínica Médica e Pediatria, durante o período de 1994 a 2002, 7191 acidentes causados por animais peçonhentos, dos quais $383(5,32 \%)$ por aranhas, assim distribuídos:

$\begin{array}{lrr}\text { Phoneutria } & 126 & 32,9 \% \\ \text { Lycosa } & 23 & 6,0 \% \\ \text { Loxoceles } & 8 & 2,1 \% \\ \text { Megalomorphae } & 11 & 2,8 \% \\ \text { Não Identificadas } & 215 & 56,1 \%\end{array}$

\section{ACIDENTES POR ARANHAS DO GÊNERO PHONEUTRIA}

As aranhas do gênero Phoneutria são conhecidas pelo nome popular de "armadeiras", devido à posição que assumem, quando se encontram em perigo, erguendo as patas dianteiras e apoiando-se nas traseiras, apresentando comportamento agressivo ao enfrentarem seus inimigos.

São as responsáveis pelo maior número de acidentes no Estado de São Paulo, porém, embora produzam veneno potente, raramente ocasionam acidentes graves.

Não constroem teia geométrica, caçam principalmente à noite. Os acidentes ocorrem, frequientemente, dentro das residências e nas suas proximidades, ao se lidar com materiais de construção, entulhos, lenha, cachos de banana, caixotes de frutas.

Estudos experimentais demonstraram que o veneno atua basicamente sobre os canais de sódio, induzindo despolarização das fibras musculares e de terminações nervosas, sensitivas e motoras do sistema nervoso autônomo, ocasionando liberação de catecolaminas e acetilcolina.

\section{Quadro Clínico}

Predominam as manifestações locais. A dor, sintoma mais freqüente, ocorrendo imediatamente após a picada, desde leve até muito intensa, quase insuportável, pode irradiar-se à raiz do membro acometido, e acompanhar-se de parestesias. No local picado, podese observar edema, eritema e sudorese ao redor dos dois pontos de inoculação.

As picadas ocorre mais freqüentemente nas extremidades dos membros, não evoluindo a lesão para necrose.

De acordo com a gravidade, os acidentes podem se classificar em leves, moderados ou graves, sendo estes bastante raros e somente observados em crianças. (Quadro I).

\section{Tratamento}

O tratamento visa combater sintomas do envenenamento, neutralizar o veneno circulante e dar suporte às condições clínicas do paciente.

$\mathrm{O}$ combate à dor deve ser sempre realizado, podendo ser usados analgésicos por via oral ou parenteral e/ou anestésicos locais, sem vasoconstritor.

A soroterapia está formalmente indicada em crianças menores que sete anos de idade, com acidentes moderados e em todos os acidentes graves. Deve ser aplicada pela via endovenosa, sem diluição, na dose de 2-4 ampolas para os casos moderados e de 5-10 ampolas nos casos graves, sendo a mesma dose utilizada para adultos e crianças.

O paciente deve ser internado para melhor controle dos dados vitais, parâmetros hemodinâmicos e respiratórios e tratamento de suporte das complicações associadas.

\section{Diagnóstico Laboratorial}

Nos poucos relatos de acidentes com manifestações sistêmicas, têm sido descritos leucocitose com neutrofilia, hiperglicemia e alterações de ECG.

\section{Prognóstico}

O prognóstico é bom. Crianças, bem como idosos devem ser mantidos em observação por período de pelo menos $6 \mathrm{~h}$, em ambiente hospitalar. Os óbitos são excepcionais. 


\begin{abstract}
Quadro I: Acidentes por aranhas do gênero Phoneutria - Classificação quanto à gravidade, manifestações clínicas, tratamento geral e específico

\begin{tabular}{l|l} 
Classificação & \multicolumn{1}{c}{ Manifestações Clínicas } \\
Leve & $\begin{array}{l}\text { Dor local na maioria dos casos, eventualmente, } \\
\text { taquicardia e agitação }\end{array}$ \\
Moderado & $\begin{array}{l}\text { Quadro local associado a: sudorese e/ou vômitos } \\
\text { ocasionais e/ou agitação e/ou hipertensão arterial } \\
\text { (todas de pequena intensidade) }\end{array}$ \\
Grave & $\begin{array}{l}\text { Além das citadas acima, apresenta uma ou mais } \\
\text { das seguintes manifestações: sudorese profusa, } \\
\text { vômitos intensos, priapismo, convulsões, coma, } \\
\text { insuficiência cardíaca, bradicardia, choque e/ou } \\
\text { edema pulmonar agudo }\end{array}$
\end{tabular}

\begin{tabular}{l|l} 
Tratamento Geral & $\begin{array}{c}\text { Tratamento } \\
\text { Especifico }\end{array}$
\end{tabular}

Observação clínica

Anestésico local e/ou analgésico

Internação hospitalar

Anestésico local e/ou analgésico

Soro Antiaracnídico

2-4 ampolas IV

Unidade de Cuidados

Intensivos

Soro Antiaracnídico

5-10 ampolas IV
\end{abstract}

Fonte: Brasil. Ministério da Saúde. Manual de Diagnóstico e Tratamento de Acidentes por Animais Peçonhentos. Brasília, 1998

\section{ACIDENTES POR ARANHAS DO GÊNERO LOXOSCELES}

Conhecidas popularmente como aranhas marrons, têm hábitos noturnos, alojando-se em lugares quentes e secos, tais como sob cascas de árvores, telhas e tijolos empilhados, atrás de quadros e móveis, cantos de parede, cortinas, rodapés, roupas penduradas, roupas de cama e banho, sempre ao abrigo da luz direta. Constroem teias irregulares, com aspecto de algodão esfiapado, e alimentam-se de pequenos insetos, moscas, pernilongos, cupins, traças e pulgas. São aranhas não agressivas, picando apenas quando se sentem ameaçadas, como quando comprimidas contra o corpo da vítima.

O veneno da Loxosceles sp (aranha-marrom) possui atividades hemolítica e dermonecrótica, que parecem ser causadas pela esfingnomielinase-D (fosfolipase D) que, por ação direta ou indireta, atua sobre os constituintes das membranas das células, principalmente do endotélio vascular ou hemácias. Em virtude dessa ação, são ativadas as cascatas do sistema complemento, da coagulação e das plaquetas, desencadeando intenso processo inflamatório no local da picada, acompanhado de obstrução de pequenos vasos, edema, hemorragia e necrose local. Admitese, também, que a ativação desses sistemas participa da patogênese da hemólise intravascular disseminada, observada nas formas mais graves de envenenamento.

\section{Diagnóstico Diferencial}

Considerando que apenas $30 \%$ dos casos suspeitos de acidente loxoscélico são confirmados, é fundamental a atenção no diagnóstico diferencial, principalmente com:

- Infecção de pele (bacteriana ou viral), como celulite, erisipela e herpes.

- Dermatite de contato

- Picadas de inseto ou por outras aranhas.

\section{Quadro Clínico}

A picada é praticamente imperceptível e raramente se evidencia lesão imediata. Os sintomas locais evoluem lentamente, e, nas primeiras horas, lembram picada de inseto, sendo, por isso, pouco valorizados tanto pelo paciente como pelo profissional de saúde. A picada pode evoluir para duas formas clínicas.

\section{Forma Cutânea}

Na grande maioria dos casos, os sinais e sintomas são restritos ao local acometido. Na apresentação típica do loxoscelismo, logo após a picada, o paciente refere dor com sensação de "queimadura como de cigarro". Após algumas horas (aproximadamente duas a oito), a dor se intensifica, sendo relacionada à isquemia e vasoespasmo, podendo aparecer prurido, formigamento, eritema e edema. Este pode ser discreto ou atingir todo o membro, possuindo consistência endurada. 
O eritema dá lugar a uma mancha de aspecto violáceo, de limites mal definidos, onde coexistem áreas esbranquiçadas (isquêmicas) e áreas vinhosas (hemorrágicas), denominada "placa marmórea" ou "placa livedóide". Gradualmente, a placa sofre enduração, escurece, o centro se deprime, formando uma escara que vai se soltando pelas bordas, dando lugar a uma úlcera com características necróticas, processo que pode levar de uma a duas semanas.

Pode ocorrer, na evolução, aparecimento de bolhas com conteúdo seroso ou hemorrágico e pequenas vesículas, às vezes, de aspecto herpetiforme. Com o passar dos dias, ocorre diminuição do edema e da dor.

A lesão ulcerada granula lentamente, levando de seis a oito semanas ou até mais, muitas vezes necessitando de plástica reparadora.

A apresentação dos sinais locais pode variar nas primeiras 24 a 72 h após a picada, constituindo dado importante para efeitos de classificação e tratamento.

a) Lesão incaracterística: bolha de conteúdo seroso, edema rubor e prurido, com ou sem dor em queimação

b) Lesão sugestiva: equimose, enduração e dor em queimação

c) Lesão característica: ponto de necrose, necrose, bolha hemorrágica, isquemia (nas primeiras horas), placa marmórea

Mais raramente, o loxoscelismo cutâneo pode se acompanhar por febre, astenia, exantema do tipo escarlatiniforme, naúseas e vômitos.

\section{Forma cutaneovisceral}

É bem menos freqüente, ocorrendo dentro das primeiras 24 a $48 \mathrm{~h}$ após a picada, podendo não haver relação entre as manifestações locais e as sistêmicas.

Geralmente, acompanha-se de febre, calafrios, mal-estar, fraqueza, náuseas, vômitos, mialgia, artralgia, exantema, além das manifestações decorrentes da hemólise intravascular: anemia aguda, icterícia, hemoglobinúria, e, eventualmente, sangramento, decorrentes da plaquetopenia e hipofibrinogenemia.

Os casos graves podem evoluir para insuficiência renal aguda, de etiologia multifatorial (diminuição da perfusão renal, hemoglobinúria e CIVD), principal causa de óbito no loxoscelismo.

\section{Diagnóstico Laboratorial}

Não há exames laboratoriais rotineiros, que diagnostiquem o loxoscelismo cutâneo.
$\mathrm{Na}$ forma sistêmica, os exames mais importantes são aqueles que dizem respeito à hemólise intravascular: anemia, hiperbilirrubinemia, hemoglobinemia sérica, diminuição da haptoglobina, hemoglobinúria, plaquetopenia, diminuição do tempo de protrombina e aumento dos produtos de degradação da fibrina.

Pode ser observada leucocitose, inclusive com reação leucemóide.

Havendo comprometimento da função renal, podem ser detectados aumento nos níveis sanguíneos de uréia e creatinina, bem como do potássio.

\section{Tratamento}

A indicação do antiveneno é controvertida na literatura. Dados experimentais revelam que a eficácia da soroterapia é reduzida após $36 \mathrm{~h}$ da inoculação do veneno. As recomendações para utilização do antiveneno dependem da classificação de gravidade, como é mostrado no Quadro II.

Além da soroterapia, tem sido recomendado o uso de corticoesteróide local (como antiinflamatório) e por via sistêmica (com o objetivo de proteger a membrana da hemácea, inibindo a hemólise, e de diminuir a viscosidade sanguínea).

A dapsona tem sido indicada nas formas cutâneas graves, em associação com a soroterapia, como modulador da resposta inflamatória para redução do quadro local, na dose de 50 a $100 \mathrm{mg} / \mathrm{dia}$, via oral por duas semanas aproximadamente. Devido ao risco potencial de a dapsona desencadear metemoglobinemia e hemólise, o paciente deve ser acompanhado do ponto de vista clínico e laboratorial, durante o período de administração da droga.

Se houver evidências de hemólise intravascular, impõe-se hidratação adequada e alcalinização da urina, no sentido de prevenir a precipitação intratubular de hemoglobina e uma possível necrose tubular aguda hemoglobinúrica, além do controle rigoroso da hemoglobina e hematócrito.

Os problemas decorrentes do consumo dos fatores de coagulação, como sangramentos causados pela plaquetopenia e hipofibrinogenemia, deverão ser tratados conforme a necessidade.

Em relação à lesão cutânea, está indicada cuidadosa assepsia, bem como imobilização e elevação do membro atingido, compressas frias, analgésicos e antiinflamatórios locais.Muitas vezes, é necessária a intervenção da Cirurgia Plástica para a realização de debridamentos e até de enxertia de pele. 
Quadro II: Acidentes por aranhas do gênero Loxosceles classificação quanto à gravidade, manifestações clínicas tratamento geral e específico

\begin{tabular}{|c|c|c|}
\hline Classificação & Manifestações Clínicas & Tratamento \\
\hline Leve & $\begin{array}{l}\text { - Lesão incaracterística, sendo a Loxosceles identificada } \\
\text { como causador do acidente) } \\
\text { - Lesão local sugestiva } \\
\text { - Sem comprometimento do estado geral } \\
\text { - Sem alterações laboratoriais }\end{array}$ & $\begin{array}{l}\text { - Sintomáticos: } \\
\text { Analgésico } \\
\text { Antiinflamatório local } \\
\text { - Acompanhamento até } 72 \text { h após picada }\end{array}$ \\
\hline Moderado & $\begin{array}{l}\text { - Com ou sem identificação da Loxosceles no momento } \\
\text { da picada } \\
\text { - Lesão sugestiva com rash cutâneo ou lesão } \\
\text { característica < } 3 \mathrm{~cm} \text { de diâmetro } \\
\text { - Com ou sem alterações sistêmicas (febre, mal estar } \\
\text { geral, rash cutâneo, cefaléia, mialgia e outros). } \\
\text { - Sem alterações laboratoriais, sugestivas de hemólise }\end{array}$ & $\begin{array}{l}\text { - Prednisona ( } 5 \text { dias): } \\
\text { adultos: } 40 \mathrm{mg} / \mathrm{dia} \\
\text { crianças: } 1 \mathrm{mg} / \mathrm{kg} / \mathrm{dia} \text { e/ou } \\
\text { - SAAr ou SALox IV } \\
5 \text { ampolas } \\
\text { - Sintomáticos }\end{array}$ \\
\hline Grave & $\begin{array}{l}\text { - Lesão característica de instalação rápida (primeiras } 36 \text { h) } \\
\text { com > } 3 \mathrm{~cm} \text { de diâmetro e/ou } \\
\text { - Evidência de hemólise (palidez, anemia aguda, } \\
\text { icterícia) confirmada laboratorialmente. }\end{array}$ & $\begin{array}{l}\text { - SAAr ou SALox IV } \\
5 \text { ampolas (forma cutânea) } 10 \text { ampolas } \\
\text { (forma cutaneovisceral) IV } \\
\text { - Prednisona ( } 7 \text { a } 10 \text { dias): } \\
\text { adultos: } 40 \mathrm{mg} / \mathrm{dia} \\
\text { crianças: } 1 \mathrm{mg} / \mathrm{kg} / \mathrm{dia} \\
\text { - Sintomáticos }\end{array}$ \\
\hline
\end{tabular}

SALox: Soro Antiloxoscélico; SAAr : Soro Antiaracnídico

Fonte: Brasil.. Ministério da Saúde. Manual de Diagnósticoee Tratamento de Acidentes por Animais Peçonhetos. Brasilia, 1998.

\section{BIBLIOGRAFIA CONSULTADA}

1- ANTUNES E \& MÁLAQUE CM. Mecanismo de ação do veneno de Phoneutria e aspectos clínicos do foneutrismo.In: CARDOSO JCC; FRANÇA FOS; FAN HW; MÁLAQUE CM \& HADDAD Jr. V, eds. Animais peçonhentos no Brasil. Biologia, Clínica e terapêutica dos acidentes. Sarvier, São Paulo, p. 150-159, 2003.

2- AZEVEDO-MARQUES MM; CUPO P\& HERING S.E. Acidentes por animais peçonhentos. Medicina, Ribeirão Preto 25: 539-554, 1992.

3- BARBARO KC \& CARDOSO JLC. Mecanismo de ação do veneno de Loxoceles e aspectos clínicos do Loxoscelismo. In: CARDOSO JLC; FRANÇA FOS; FAN FW; MÁLAQUE CM \&
HADDAD Jr. V, eds. Animais peçonhentos no Brasil. Biologia, clínica e terapêutica dos acidentes. Sarvier, S. Paulo, p.160-174, 2003

4- BRASIL. MINISTÉRIO DA SAÚDE. FUNDAÇÃO NACIONAL DA SAÚDE. Manual de diagnóstico e tratamento de acidentes por animais peçonhentos. Brasília, 1998.

5- BUCARETCHI F. Acidentes por Phoneutria (Foneutrismo). In: SCHVARTSMAN S, ed. Plantas venenosas e animais peçonhentos. Sarvier, São Paulo, p.196-201, 1992.

6- LUCAS S. Spiders in Brazil. Toxicon 26: 759-772,1988.

7- SECRETARIA MUNICIPAL DA SAÚDE. Acidentes loxoscélicos. Protocolo Técnico e Fluxo de Atenção em Curitiba. Curitiba, 2002.

CUPO P; AZEVEDO-MARQUES MM \& HERING SE. Envenomation caused by poisonous animals: Scorpions and spiders. Medicina, Ribeirão Preto, 36: 490-497, apr./dec. 2003.

ABSTRACT: Physiopathological, clinical and therapeutic aspects of human envenomation directed to the Center for Control of Intoxication of the U.E. - HCFMRP-USP, caused by Tityus gender scorpions and Phoneutria and Loxosceles gender spiders are discussed. Specific antivenom serum should be employed, if indicated, according to the principles described to the poisonous snakes.

UNITERMS: Scorpions. Spiders. Poisoning. Antivenins. 